\title{
Influence of coexisting internal diseases on hearing loss in patients over 50 years of age
}

\author{
PIOTR ŚWIDZIŃSKI ${ }^{1, A, C-E}$, ANNA FRANKOWSKA ${ }^{2, A, B, D, F}$, BOGNA MAŁACZYŃSKA ${ }^{1, A-c}$, \\ KAMILA LINKOWSKA-ŚWIDZIŃSKA ${ }^{3, A, B, ~ D}$, ANNA HASHIMOTO ${ }^{1, B, D}$, \\ BARBARA BILIŃSKA ${ }^{1, B, C}$, ZOFIA MACIEJEWSKA-SZANIEC ${ }^{4, E, ~ F}$, PIOTR KOWAL $^{5, A, F}$, \\ ALICJA SEKULA ${ }^{1, A, G}$, BARBARA MACIEJEWSKA ${ }^{1, A, D-F}$ \\ ORCID ID: 0000-0002-3666-5931
}

${ }^{1}$ Department of Phoniatry and Audiology, Poznan University of Medical Sciences, Poland

${ }^{2}$ Department of Medical Law, Poznan University of Medical Sciences, Poland

${ }^{3}$ Department of Oral Rehabilitation, Poznan University of Medical Sciences, Poland

${ }^{4}$ Temporomandibular Disorder Clinic, Poznan University of Medical Sciences, Poland

${ }^{5}$ Neurology Clinic, Poznan University of Medical Sciences, Poland

A - Study Design, B - Data Collection, C - Statistical Analysis, D - Data Interpretation, E - Manuscript Preparation, F - Literature Search, $\mathbf{G}$ - Funds Collection

Summary Background. Presbyacusis is a physiological hearing defect progressing with age, caused by degenerative changes in the inner ear. Chronic internal diseases can change the development of age-related hearing loss.

Objectives. The aim of the study was to determine the influence of chronic internal diseases (hypertension, diabetes, hyperlipidaemia) on the process of hearing loss in people over 50 years of age.

Material and methods. 215 audiological patients with hearing loss and internal disease were compared with 80 patients with physiological hearing loss (presbyacusis). We analysed the results of hearing thresholds in the pure tone audiometry. The results were analysed in four age groups: 50-59, 60-69, 70-79 and 80+.

Results. The relation between internal chronic diseases, different age groups and $\mathrm{HL}$ for mean values of $1 \mathrm{kHz}, 2 \mathrm{kHz}, 4 \mathrm{kHz}$ and $8 \mathrm{kHz}$ frequencies showed that the greatest progression of hearing loss was caused by hypertension and diabetes. The most significant differences were found in the 50 to 59 age groups. Additional significant differences were observed in the 60-69 age range for hyperlipidaemia patients, but the significance level was smaller.

Conclusions. Each of the chronic internal diseases is distinguished by a progression of hearing loss in patients' lives after 50 years of age. Diseases such as hypertension or diabetes or hyperlipidaemia cause a considerably faster progression of hearing loss in the earlier period of life of elderly patients.

Key words: hearing loss, disease, patients.

Świdziński P, Frankowska A, Małaczyńska B, Linkowska-Świdzińska K, Hashimoto A, Bilińska B, Maciejewska-Szaniec Z, Kowal P, Sekula A, Maciejewska B. Influence of coexisting internal diseases on hearing loss in patients over 50 years of age. Fam Med Prim Care Rev 2020; 22(1): 71-74, doi: https://doi.org/10.5114/fmpcr.2020.92510.

\section{Background}

With an aging population, hearing loss $(\mathrm{HL})$ in patients over 50 years of age is becoming an increasing clinical and social problem. One-third of people over 65 years of age suffer from disabling $\mathrm{HL}$. The prevalence of $\mathrm{HL}$ is estimated at $30-40 \%$ in the population aged 65 to 74 years and at $50-80 \%$ in the population aged 75 years and older depending on the criteria for $\mathrm{HL}$ and the recruiting procedures used in the study [1]. The elderly population is rapidly growing, and more and more elderly people are visiting family practitioners.

Presbyacusis is defined as a physiological HL progressing with age, caused by degenerative changes in the inner ear and the central nervous system [2]. The processes are of an atrophic-degenerative type and involve the Corti organ, spiral ganglion, stria vascularis and the nuclei of the auditory nerve. Presbyacusis is characterised by $\mathrm{HL}$ at high frequencies, as well as a reduced understanding of speech [3]. It is a part of geriatric syndrome (GE). GEs have been viewed as conditions in which symptoms are assumed to result not solely from discrete diseases, but also from accumulated impairments in multiple systems
[4]. GE includes hearing loss, dementia, dizziness, gait disorders, urinary incontinence, osteoporosis and loss of vision [5].

$\mathrm{HL}$ can mimic a weakening of cognitive processes. Moreover, $\mathrm{HL}$ is known to exaggerate the effects of cognitive deficits and has been found to predict a more rapid cognitive decline. The prevalence of dementia, as well as hearing impairment, is increasing with age.

Auditory function can also be impaired by internal diseases, such as diabetes, hyperlipidaemia and hypertension. A combination of diabetes and sensorineural $\mathrm{HL}$ has been reported by Janssen et al. [6, 7]. Kakarlapudi et al. [8] noted that HL was more common in diabetic patients than in their age-matched controls. HL was significantly greater in diabetic subjects up to 60 years of age than healthy age-matched controls [9]. It is also suggested that diabetes may act synergistically with the processes involved in the development of age-related $\mathrm{HL}[7,9]$. The effect of hyperlipidaemia has been reported $[10,11]$. Arterial hypertension can alternatively influence presbyacusis by the agency of atherosclerosis processes and/or an increase in the intima media thickness, which can disturb the microcirculation within the inner and middle ear [12]. 


\section{Objectives}

The purpose of the study was to assess the hearing level and severity of presbyacusis in patients over 50 years of age depending on coexisting internal diseases.

\section{Material and methods}

215 audiological outpatients (430 ears, 95 females, 87 males) over 50 years of age with $\mathrm{HL}$ and one of the specific chronic internal diseases (groups $\mathrm{A}-\mathrm{C}$ ) or with presbyacusis only (group D) were included in the study. The right ear and the left ear in each patient were examined separately. Table 1 presents the number of results (ears) analysed in the various disease groups with regard to the patients' age.

\begin{tabular}{|c|c|c|c|c|}
\hline Age & $\begin{array}{l}\text { Hyperten- } \\
\text { sion (A) }\end{array}$ & $\begin{array}{l}\text { Diabetes } \\
\text { (B) }\end{array}$ & $\begin{array}{l}\text { Hyperlipi- } \\
\text { daemia (C) }\end{array}$ & $\begin{array}{l}\text { Control } \\
\text { group (D) }\end{array}$ \\
\hline 50-59 & 39 & 19 & 28 & 27 \\
\hline $60-69$ & 48 & 25 & 20 & 24 \\
\hline 70-79 & 86 & 25 & 20 & 20 \\
\hline $80+$ & 15 & 23 & 2 & 9 \\
\hline Total & 188 & 92 & 70 & 80 \\
\hline
\end{tabular}

The chronic internal diseases selected for the study were: (A) hypertension, (B) hyperlipidaemia, (C) diabetes mellitus type 2. The diagnosis was established by a general practitioner or internist. All patients delivered a medical certificate about their chronic internal disease and confirmed that they were not treated for any of the other two analysed diseases. The patients were qualified for groups if the illness had been treated for at least 2 years. Exclusion criteria included: deafness, neurodegenerative diseases, dementia, conditions that change the result of hearing tests, ontological operations and acute infections of the ears, nose and throat, as well as uncontrolled treatment of the previously mentioned internal diseases. The control group consisted of 80 patients with presbyacusis, but with no systemic or laryngological diseases (D). Group D served as the reference group in the statistical analyses. Within each group, the patients were next divided into four age subgroups: those 50-59 years of age, 60-69, 70-79 and 80+. This division was made in order to determine in which age group presbyacusis was most influenced by the given disease (out of the four chosen for the study). All patients were examined by a neurologist to establish their neurological and mental status. Some audiological examinations were carried out. The main one was pure tone audiometry (PTA) as a simple, non-invasive test. Normal HL in PTA is $0-20 \mathrm{~dB} \mathrm{HL}$. In the study, data analysis included only quantitative research in PTA.
Hearing loss for frequencies of $250 \mathrm{~Hz}$ and $500 \mathrm{~Hz}$ is mainly connected with conduction impairments, while defects in hearing for frequencies of $1 \mathrm{kHz}$ and more tend to deal with perceptive (sensoneural) impairments. This means $\mathrm{HL}$ for frequencies of $1 \mathrm{kHz}$ and more tend to concern presbyacusis. Thus, the subsequent analyses dealt with the frequencies of $1,2,4$ and $8 \mathrm{kHz}$.

Statistical analysis was performed with the Statistica 10 (StatSoft Polska), using non-parametric Anova-Manova and U Mann-Whitney tests, as well as MS Office Excel 2010 spreadsheets.

\section{Results}

The results of all patients with internal diseases were compared to the reference group of patients without any chronic internal diseases (group D). This analysis, being the general ratio for evaluating the differences with the level of significance set at $p<0.05$, suggested that the differences may occur in PTA. The analyses of hearing level were performed separately in relation to the diseases in groups A-D. The mean hearing loss (for a frequency of 1 to $8 \mathrm{kHz}$ ) with regard to the patients' age in every age group was compared to the hearing loss in compatible patients from the control group D. Table 2 presents the mean values for the hearing defects in the chosen frequencies with and without age correction for all age groups. A correction with regard to age was made with the use of correction charts [2]. Next, the relation between internal chronic diseases, different age groups and $\mathrm{HL}$ was analysed for mean values of the frequencies $1 \mathrm{kHz}, 2 \mathrm{kHz}, 4 \mathrm{kHz}$ and $8 \mathrm{kHz}$ (Figure 1).

Statistical analyses were carried out for the decades of life studied, namely $1-8 \mathrm{kHz}$ - Figure 1 presents the results.

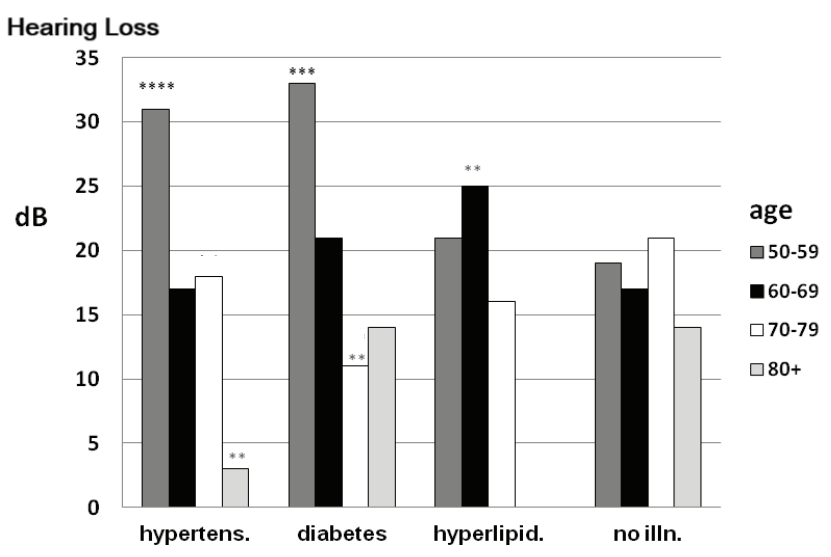

Figure 1. Age-corrected mean hearing loss in the given age and disease groups

The values for patients with internal diseases were compared with the values for the control group. Statistically significant differences can be seen in the results from the Mann-Whitney test $(* * * *-p<0.0001$; $* * *-p<0.001, * *-p<0.01$ )

\begin{tabular}{|c|c|c|c|c|c|c|c|}
\hline \multirow[t]{2}{*}{ Disease } & \multirow[t]{2}{*}{ Pure tone audiometry } & \multicolumn{6}{|c|}{ Hearing loss in $\mathbf{d B}$} \\
\hline & & $250 \mathrm{~Hz}$ & $500 \mathrm{~Hz}$ & $1,000 \mathrm{~Hz}$ & $2,000 \mathrm{~Hz}$ & $4,000 \mathrm{~Hz}$ & $8,000 \mathrm{~Hz}$ \\
\hline \multirow[t]{2}{*}{ Hypertension (A) } & no correction & 20 & 26 & 31 & 41 & 55 & 62 \\
\hline & correction & 8 & 13 & 18 & 20 & 22 & 18 \\
\hline \multirow[t]{2}{*}{ Diabetes (B) } & no correction & 25 & 32 & 35 & 44 & 61 & 61 \\
\hline & correction & 13 & 18 & 20 & 20 & 23 & 11 \\
\hline \multirow[t]{2}{*}{ Hyperlipidaemia (C) } & no correction & 24 & 29 & 32 & 37 & 55 & 49 \\
\hline & correction & 16 & 20 & 22 & 22 & 28 & 13 \\
\hline \multirow{2}{*}{$\begin{array}{l}\text { No systemic illnesses } \\
\text { (control group) (D) }\end{array}$} & no correction & 29 & 33 & 35 & 40 & 53 & 63 \\
\hline & correction & 18 & 22 & 20 & 20 & 22 & 19 \\
\hline
\end{tabular}


These results suggest that statistically significant $\mathrm{HL}$ in patients $50-59$ years of age occurs in patients with hypertension (A) $(p<0.0001)$ and diabetes mellitus type 2 (B) $(p<0.001)$. Additional significant differences were observed in the 60-69 age range for group $\mathrm{C}$ (hyperlipidaemia patients), but the significance level was smaller $(p<0.01)$.

The study showed that $\mathrm{HL}$ in patients suffering from chronic internal diseases is less progressive with age, especially after 70, when compared to hearing loss in patients without other illnesses. Thus, it appears that HL or presbyacusis may be stimulated and accelerated, especially by diabetes mellitus type 2 and hypertension, mostly in the $6^{\text {th }}$ decade of life. Later, in the $8^{\text {th }}-9^{\text {th }}$ decade, the effect of severe deterioration of HL did not appear.

\section{Discussion}

People with presbyacusis suffer from sensorineural HL. Besides having problems with the auditory system, patients at the age of $50+$ often suffer from other diseases. It is always important to ask about any ear surgeries in the past, as well as ear diseases (e.g. otosclerosis), to exclude conductive HL [13].

The study shows that the increase in sensorineural $\mathrm{HL}$ in groups with internal diseases $(A-C)$ is different than in the healthy group (D) and depends on age.

In the treatment of hypertension, besides the tension itself and its hypertrophic changes, the application of hypotensive drugs may also play a crucial role. Their effect can be both negative (ototoxicity) and positive (long-term effects of blood pressure reduction). In the current study, the progress of $\mathrm{HL}$ in the hypertension group appeared greatest in the 50-59 age group, while the least progress of hearing loss was observed in the group of patients aged $80+$. This problem was observed for all the recorded frequencies, ranging from $1 \mathrm{kHz}$ to $8 \mathrm{kHz}$. In diabetic patients, the greatest progression of HL occurred in patients 50-59 years of age, too. According to other researchers, hearing loss often occurs in patients with diabetes mellitus type $2[12,14,15]$. This observation is also confirmed by our findings. Greater $\mathrm{HL}$ for higher frequencies was observed in the $6^{\text {th }}$ and $7^{\text {th }}$ decades of life. However, in the $8^{\text {th }}$ and $9^{\text {th }}$ decades of life, a progression of HL was observed for all frequencies $[9,15]$. The 5-year prospective study of Evans et al. proved that a hearing defect for higher frequencies was most prevalent in patients with dyslipidaemia up to 60 years of age [10]. In turn, in patients over 60 years of age, $\mathrm{HL}$ was less prevalent. Similar results were observed in our study. It should be emphasised that in most of the cited works, their authors undoubtedly confirm the influence of internal diseases on the progression of hearing loss in the elderly. However, they do not analyse the progression in subsequent time intervals. The fluctuating process of deepening $\mathrm{HL}$ in various systemic diseases can be used to monitor and predict the effects of systemic diseases on the hearing organ. Each of the systemic diseases leads to hearing deterioration, but the most severe $\mathrm{HL}$ is observed in people over 50 years of age (groups A, B) and 60 years of age (C). The control of biochemical parameters of cardiometabolic risk could be considered in adolescent and adults as a prevention activities implemented by family doctors among to prevent rapid HL in elderly $[16,17]$.

$\mathrm{HL}$ has been proposed as a modifiable risk factor for dementia, similar to hypertension, diabetes mellitus and dyslipidaemia [18]. Dementia has become the greatest global challenge for health and social care [19], but large groups of patients still have undiagnosed cognitive impairment [20]. This is a clinical syndrome that includes the decline of cognitive and conscious states and is caused by many neurodegenerative diseases, of which Alzheimer's disease (AD) - a progressive, unremitting and neurodegenerative disorder, and vascular dementia (VD) - mainly caused by hypertension and arteriosclerosis, are the most common ( $A D$ vs VD: $50-70 \%$ vs $20 \%$ ) [1]. HL is known to exaggerate the effects of cognitive deficits and has been found to predict a more rapid cognitive decline. The prevalence of dementia, as well as hearing impairment, increases with age. As a consequence, older people are often affected by both conditions. Moreover, hypertension, diabetes and hyperlipidaemia lead to vascular problems and can also take part in vascular dementia.

\section{Limitations of the study}

There are some limitations of the study. First of all, waist circumference, body weight or body mass index (BMI) were not analysed in the study. It is known that associations exist between obesity and $\mathrm{HL}$ [21], and the relationship between metabolic syndrome in children and adolescents and cardiovascular diseases, diabetes and atherosclerosis has been confirmed in clinical studies. Moreover, it could be interesting to evaluate the prevalence of $\mathrm{HL}$ in patients with metabolic syndrome not only with hypertension. Secondly, cigarette smoking may affect hearing sensitivity through its effects on the vasculature supplying the auditory system [22]. However, smoking habits were not analysed. Another limitation was the time course of internal diseases. The correlation between severity of $\mathrm{HL}$ and time course of coexisting diseases could show some interesting data, too.

Detecting $\mathrm{HL}$ and reducing any disability caused by hearing impairment in elderly patients could decrease their cognitive problems and improve the quality of life. It could be important for general practitioners to remember that $\mathrm{HL}$ can be an underdiagnosed problem in patients with internal diseases, especially in those over 50 years of age.

\section{Conclusions}

1. Each of the evaluated chronic internal diseases leads to a progression of $\mathrm{HL}$ and accelerates the process called presbyacusis.

2. The deterioration of hearing level in people with chronic internal diseases such as hypertension or diabetes mellitus type 2 or hyperlipidaemia is evident in subsequent decades of patients' lives. The diseases cause considerably faster progression of $\mathrm{HL}$ in the earlier period of life than in later one - the greatest after 50 year, most prevalent in patients aged up to 60 .

Source of funding: This work was funded from the authors' own resources.

Conflicts of interest: The authors declare no conflicts of interest.

\section{References}

1. Lemke U. Hearing impairment in dementia - how to reconcile two intertwined challenges in diagnostic screening. Audiol Res 2011; 1(1): e15, doi: 10.4081/audiores.2011.e15.

2. Pruszewicz A. Audiologia kliniczna-zarys. 4rd ed. Poznań: Wydawnictwo Naukowe Uniwersytetu Medycznego; $2010: 417-422$ (in Polish).

3. Tavanai E, Mohammadkhani G. Role of antioxidants in prevention of age-related hearing loss: a review of literature. Eur Arch Otorhinolaryngol 2017; 274(4): 1821-1834.

4. Tinetti ME, Williams CS, Gill TM. Dizziness among older adults: a possible geriatric syndrome. Ann Intern Med 2000; 132 : 337-344.

5. Won CW, Yoo HJ, Yu SH, et al. Lists of geriatric syndromes in the Asian-Pacific geriatric societies. Europ Geriatric Med 2013; 4(5): 335-338. 
6. Kurien M, Thomas K, Bhanu TS. Hearing threshold in patients with diabetes mellitus. J Laryngol 1989; 103: 164-168.

7. Janssen GM, Maassen JA, van Den Ouweland JM. The diabetes-associated 3243 mutation in the mitochondrial tRNA(Leu(UUR)) gene causes severe mitochondrial dysfunction without a strong decrease in protein synthesis rate. J Biol Chem 1999; 274: $29744-29748$.

8. Kakarlapudi V, Sawyer R, Staecker H. The effect of diabetes on sensorineural hearing loss. Otol Neurotol 2003; 24: 382-386.

9. Vaughan N, James K, McDermott D, et al. A 5-year prospective study of diabetes and hearing loss in a veteran population. Otol Neurootol 2006; 27(1): 37-43.

10. Evans MB, Tonini R, Shope CD, et al. Dyslipidemia and auditory function. Otol Neurotol 2007; 27: 609-614.

11. Antonelli AR, Bonfioli F, Garrubba V, et al. Audiological findings in elderly patients with chronic renal failure. Acta Otolaryngol Suppl 1990; 476: 54-68.

12. Jędras M. Wpływ schorzeń ogólnoustrojowych na przebieg presbyacusis [doctoral dissertation]. Poznań: University of Medicine; 2011 (in Polish).

13. Saki N, Kardoni M, Karimi M, et al. Short-term hearing results in adults after stapedotomy. Fam Med Prim Care Rev 2019; 21(2): 144-148.

14. Betlejewski S. Niedosłuch związany z wiekiem (presbyacusis) jako problem społeczny. Otolar Pol 2006; 6 (in Polish).

15. Pośpiech L, Gawron W, Orendorz-Frączkowska K. Uszkodzenia słuchu w chorobach neurologicznych i ogólnoustrojowych. Audiologia kliniczna. Łódź: Mediton; 2005: 337-344 (in Polish).

16. Banaś I, Lewek P, Kardas P. In which group of children and adolescents should a family doctor look for metabolic syndrome? Fam Med Prim Care Rev 2016; 18(3): 217-220.

17. Matej-Butrym A, Butrym M, Jaroszyński A. Self-assessment of compliance with physician recommendations and glycaemic control in patients with type 2 diabetes. Fam Med Prim Care Rev 2015; 17(2): 111-114.

18. Panza F, Solfrizzi V, Seripa D, et al. Age-related hearing impairment and frailty in Alzheimer's disease: interconnected associations and mechanisms. Front Aging Neurosci 2015; 7: 113.

19. Livingston G, Sommerlad A, Orgeta V, et al. Dementia prevention, intervention, and care. Lancet 2017; 390(10113): $2673-2734$.

20. Chorążyczewska E, Sapilak B. The incidence of disorders of the cognitive functions in patients over 65 years of age in primary medical care with the use of screening tests: clock drawing test and MMSE. Fam Med Prim Care Rev 2015; 17(2): 86-89.

21. Aghazadeh-Attari J, Mansorian B, Mirza-Aghazadeh-Attari M, et al. Association between metabolic syndrome and sensorineural hearing loss: a cross-sectional study of 11,114 participants. Diabetes Metab Syndr Obes 2017; 10: 459-465.

22. Cruickshanks KJ, Klein R, Klein BEK, et al. Cigarette smoking and hearing loss: the epidemiology of hearing loss study. JAMA 1998; 279(21): 1715-1719.

Tables: 3

Figures: 1

References: 31

Received: 2.07.2019

Reviewed: 10.07.2019

Accepted: 3.10 .2019

Address for correspondence:

Barbara Maciejewska, MD, PhD

Katedra i Klinika Foniatrii i Audiologii

Uniwersytet Medyczny w Poznaniu

ul. Przybyszewskiego 49

60-355 Poznań

Tel.: +48 504 772-652

E-mail: barbaramaciejewska@ump.edu.pl 